\title{
SENSIBLE DIAGNOSES FOR SENSIBLE CLINICIANS: THE NEW EDITION OF THE PSYCHODYNAMIC DIAGNOSTIC MANUAL (PDM-2)
}

\begin{abstract}
The article analyzes psychodynamic clinical models focused on clinical case formulation and treatment planning, offers practitioners empirically grounded and clinically validated alternatives to such personality maps as the Diagnostic and Statistical Manual of Mental Disorders (DSM) and the International Classification of Diseases (ICD). The PDM-2 diagnostic model aims to provide a systematic description of healthy functioning and personality disorders; individual profiles of mental functioning (including patterns of relationships with other people, understanding and expressing feelings, overcoming stress and anxiety, regulating impulses, observing one's own emotions and behavior and forming moral judgments, etc.); as well as symptom patterns, including differences in each person's subjective experience of symptoms and in the subjective experiences of treating therapists.
\end{abstract}

Keywords: psychodynamics, diagnosis, feeling, stress and anxiety

The publication of the first edition of the Psychodynamic Diagnostic Manual (PDM) in 2006 provided an exciting opportunity for psychoanalysts to discuss a somewhat controversial term: diagnosis. Nancy McWilliams (2011) remembers that some therapists consider it almost a" "swear-word". For example, Irwin Hoffman (2009), criticising PDM, states that any categorisation of a patient is a way of drying up the richness and variety of his human experience. I reply that, of course, synthesis and simplification are interior to any system of classification - Virginia Woolf (1922) said it is no use trying to sum people up, "it is useless to pretend to summarise a person" - but why would creating families of concepts or descriptions mean "drying up" the human experience? It infers finding out which elements of the unrepeatable individual uniqueness can be aggregated in such a way as to confront shared scientific knowledge accumulated over time. And this is meant to be there as a treatment mode to be chosen by clinicians and for researchers to develop studies on the effectiveness of therapies.

Yes, "which" diagnosis should we choose? The purpose of this discussion is to" 
"infect" the readers of Communicate with the idea of diagnosis that underlies the new edition of the PDM: the PDM-2, published in 2017 in the United States and translated in Italy in 2018. Incidentally, I 'can't help but notice how the name of this publication, Communicate, underlies what I call "sensible diagnosis for sensible clinicians". This is because the idea of diagnosis completely immerses in its etymological root: knowledge (-gnosis) through (dia-) - through relationship, i.e. communication.

In his General Psychopathology, the philosopher and psychiatrist Karl Jaspers (1913) states that, for the clinician, "all diagnostic systems must represent a torment". This phrase taught me a lot, pushing me to consider this "torment" as a tension: the diagnostic tension between the need to bring the patient back to a general category and, at the same time, to his uniqueness. When, speaking of a patient, I say that he or she has a" "narcissistic" or "obsessive" personality, or that he or she has an anxiety disorder (to mention known diagnoses), I am speaking of him or her as belonging to an" "ideal" community of symptoms and structures. This diagnostic gestalt is never perfectly superimposable on the person I have in front of me, nevertheless essential for understanding and treating that patient. This should not make me forget that I am talking about the unique way in which that patient deals with the symptoms and dynamics of narcissism, obsessiveness or anxiety. That is why in our clinical work, teaching and supervision, we must achieve and maintain a binocular vision, capable of including the general and the particular, the diagnostic label and the case formulation. It is the only way not to "shipwreck" the diagnostic process between the Scylla of bureaucratic compilation and the Charybdis of idiosyncratic and self-referential jargon. Both mortify the professional identity of the clinician and mitigate or distort his ability to detect and describe the characteristics and mental functioning of the patient, thus jeopardising the clinical relationship.

For this reason, I have put a lot of effort into the promotion and development in the Italian context of" "sensible and sensitive" diagnostic systems, first the Shedler-Westen Assessment Procedure (SWAP), aimed at personality assessment, and now the PDM2. My bet is to bring back into the act of diagnosing not only interest but also passion, challenge and pleasure.

Suppose that psychodynamic diagnosis is a long journey. In that case, we imagine that it began in 1915 with these words of Freud: "We do not want simply to describe and classify phenomena, but to conceive of them as clues to a play of forces taking place in the psyche". To be of actual use for clinicians, a diagnostic system must: consider psychopathology in the context of personality; conceive symptoms jointly with mental 
functioning as a whole; collecting the ' 'patient's resources and not only his difficulties; the diagnosis in the life cycle (from early childhood to old age); consider the relational elements of the diagnostic act; consider the subjective experience that the patient has of his symptoms; enhance the role of the disciplined subjectivity of the clinician in the diagnostic formulation; contemplate, as already mentioned, both the synthetic value of the label and the specificity of the case narrative; promote clinical training (diagnosis as a moment of supervision) and make clinical and research dialogue. Above all, a diagnosis should never be thought of independently from treatment. When we quote Peter Fonagy's well-known formula: what works for whom, we must always think of the identical and hidden formula: what does not work for whom. The goodness of a diagnosis lies in its clinical translatability: as a synthesis of the problems and resources of a patient and as a guide to identifying the most appropriate therapeutic approach. If we isolate the diagnostic label from the therapeutic goals it contains, we risk making like the fool who, when the wise man points to the moon, looks at the finger.

When the first edition of the Psychodynamic Diagnostic Manual was published, psychiatric nosography was dominated by one approach, the Diagnostic and Statistical Manual of Mental Disorders. A categorical, rather than theoretical, and descriptive approach - based on the criteria of presence/absence of symptoms - is developed to identify, in a discrete manner, the respective mental disorders. Descriptiveness and not theoretical ways aimed to remove any remnants of psychoanalysis, minimising inferentiality - traditionally considered a "nuisance" variable. Over decades, each edition of the DSM included more and more disorders, promoting, along with an enrichment of the diagnostic landscape. Hence, also, progressive inflation of diagnoses and an overly sharp distinction between" "healthy" and "sick", "normality" and "pathology" (Frances, 2013). The PDM project, on the contrary, aims to offer the clinician a psychodynamic approach based on clinical literature and empirical research, which respects "disciplining" the subjectivity of the patient and the therapist and can describe the full range of individual functioning, from the most manifest aspects to the deep elements underlying the most characteristic emotional, cognitive, interpersonal and social patterns.

On the occasion of the release of the DSM-5, the American Psychoanalytic Association website stated: "There is a place in the field of mental health for classifying patients based on descriptions of their symptoms, the course of their pathology, and other objective elements. However, like psychoanalysts, we know that each patient is unique. No two individuals with the same disorder, whether depression, complicated 
grief, anxiety, or any other type of mental pathology, will ever have the same potential, treatment needs, or responses to therapeutic interventions. Whether or not one values descriptive, diagnostic nomenclatures such as the DSM-5, psychoanalytic diagnostic assessment is a complementary and necessary assessment pathway that aims to provide a deep understanding of the complexity and uniqueness of each individual and should be part of every 'patient's diagnostic assessment for it to be accurate and complete. (...) We recommend the PDM to all mental health professionals interested in drawing a diagnostic picture that describes both the overt and profound aspects of an 'individual's symptom patterns, personality, and emotional and social functioning" (apsa.org, October 2013, cited in Lingiardi, McWilliams, 2017")."

With a new, expanded, and completely revamped edition, PDM-2 aims to reaffirm and reinforce the intentions of a symptom-oriented diagnosis and attentive to the specifics of the individual and their mental functioning at different stages of the life cycle. With Nancy McWilliams, we have thus coordinated several task forces that have given rise to specific sections: Adults, Adolescents (12-18), Childhood (4-11), Early Childhood (0-3), Seniors, plus a final section entirely devoted to Assessment Tools and Clinical Cases. In Table 1, I report the structure of the Manual schematically:

Table 1. General Structure of the Psychodynamic Diagnostic Manual (PDM2)

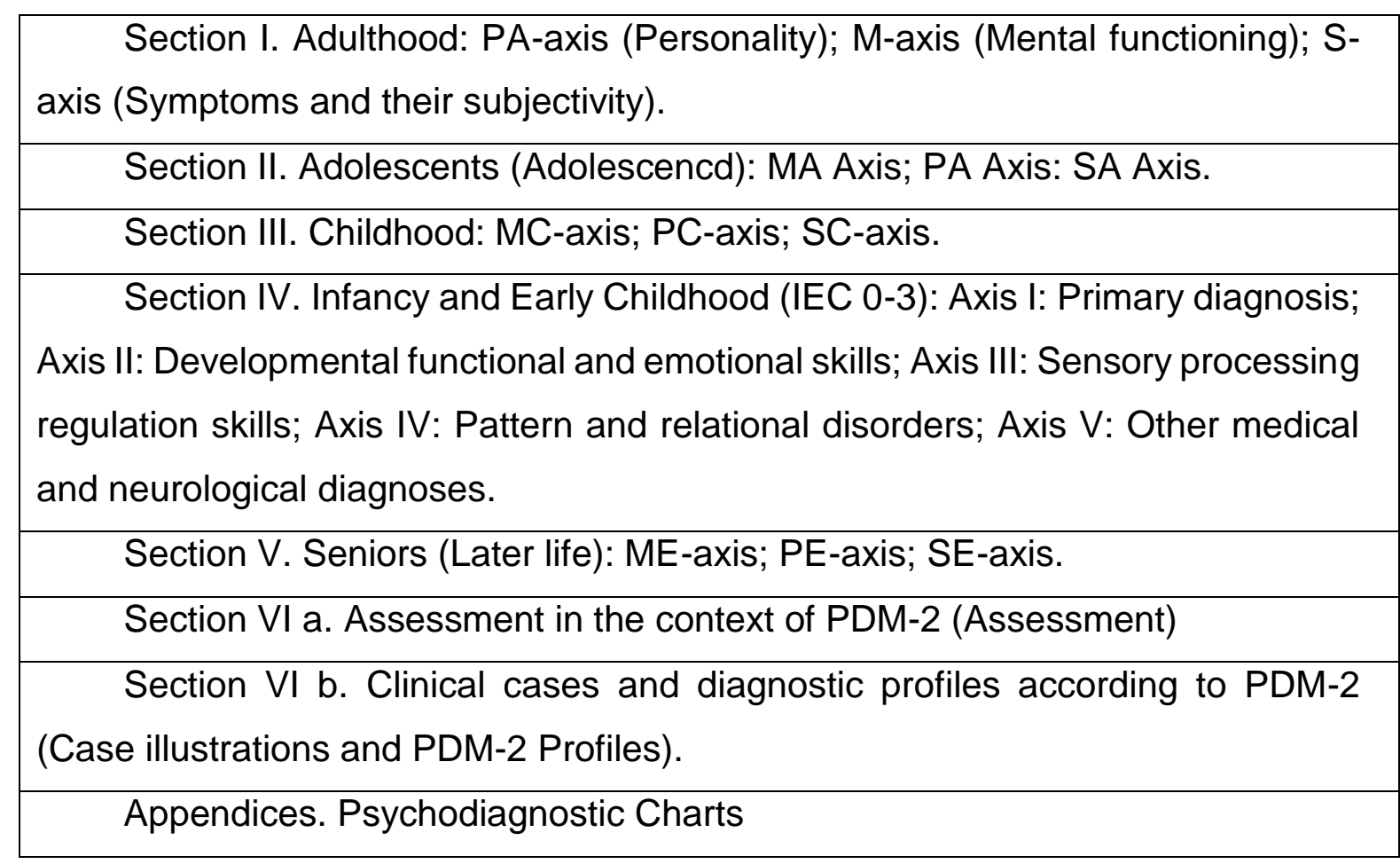

Like its predecessor, PDM-2 is intended more as a taxonomy of "people" than "a 
taxonomy of disorders". Its purpose is to provide the tools for in-depth clinical understanding in case formulation and treatment planning, especially for those cases where psychotherapy is the most recommended modality of intervention. The PDM-2 offers the clinician-diagnostician the possibility to describe his patients in a systematic and specific way according to three axes: the level of organisation and personality syndromes (P-axis); the profile of mental functioning (considering 12 mental functions) (M-axis); the symptom patterns, including the 'patient's subjective experience of his symptoms and the possible emotional responses of the therapist (S-axis). In addition, each age group has its descriptors: for example, I report in Table 2 the scheme of the adolescent section (Axis MA, PA, SA).

Table 2. Multiaxial structure of PDM-2 - Adolescent Section

\begin{tabular}{|c|c|c|}
\hline $\begin{array}{l}\text { MA axis } \\
\text { Profile of mental } \\
\text { functioning }\end{array}$ & $\begin{array}{c}\text { PA axis } \\
\text { Levels of personality } \\
\text { organisation and personality } \\
\text { spectrums/styles/syndromes }\end{array}$ & $\begin{array}{c}\text { SA axis } \\
\text { Symptom patterns (only } \\
\text { macro } \\
\text { only the macro- } \\
\text { categories) }\end{array}$ \\
\hline 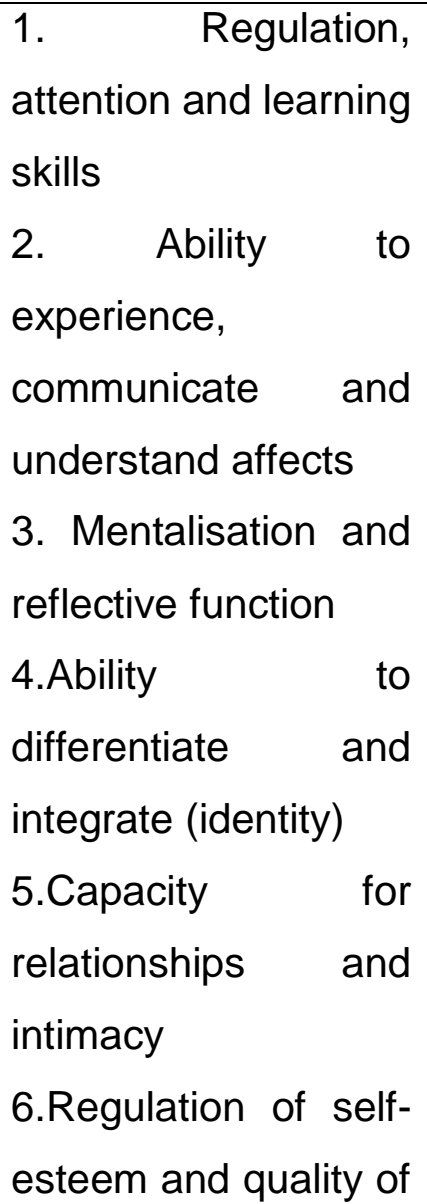 & $\begin{array}{l}\text { - Emerging "'normal' personality } \\
\text { styles (healthy level) } \\
\text { - Mildly dysfunctional emerging } \\
\text { personality styles (neurotic level) } \\
\text { - Emerging dysfunctional } \\
\text { personality styles (borderline } \\
\text { level) } \\
\text { - Emerging } \\
\text { dysfunctional personality styles } \\
\text { (psychotic level) } \\
\text { Internalising spectrum } \\
\text { Depressive personalities } \\
\text { Anxious-avoidant personalities } \\
\text { Schizoid personalities }\end{array}$ & $\begin{array}{l}\text { SA0 Healthy responses } \\
\text { SA01 Developmental and } \\
\text { adaptive crises } \\
\text { SA1 Disorders with } \\
\text { predominantly psychotic } \\
\text { manifestations } \\
\text { SA2 Mood disorders } \\
\text { SA27 Suicidality } \\
\text { SA28 Non-suicidal self- } \\
\text { harm Disorders } \\
\text { SA3 related to } \\
\text { predominantly } \\
\text { anxiety } \\
\text { SA4 Disorders related to life } \\
\text { events and stressful } \\
\text { conditions SA Somatic symptom } \\
\text { SA5 }\end{array}$ \\
\hline
\end{tabular}




\begin{tabular}{|c|c|c|}
\hline $\begin{array}{l}\text { nternal experience } \\
\text { 7.Ability to control } \\
\text { and regulate } \\
\text { mpulses } \\
\text { 3.Defensive } \\
\text { unctioning } \\
\text { 9.Adaptive capacity, } \\
\text { esilience and } \\
\text { osychological } \\
\text { esources } \\
\text { 10.Capacity for self- } \\
\text { observation } \\
\text { (psychological } \\
\text { mindset) } \\
\text { 11.Ability to construct } \\
\text { and use standards } \\
\text { and ideals } \\
\text { Meaning and } \\
\text { directionality }\end{array}$ & $\begin{array}{l}\text { Antisocial-psychopathic } \\
\text { personalities } \\
\text { Narcissistic personalities } \\
\text { Paranoid personalities } \\
\text { Borderline- deregulated } \\
\text { spectrum } \\
\text { Impulsive-histrionic personalities } \\
\text { Borderline personalities } \\
\text { Dependent-victimised } \\
\text { personalities } \\
\text { Personality style } \\
\text { Obsessive-compulsive } \\
\text { personalities }\end{array}$ & $\begin{array}{l}\text { disorder and related } \\
\text { disorders } \\
\text { SA8 Psychophysiological } \\
\text { disorders } \\
\text { SA81 Nutrition and eating } \\
\text { disorders } \\
\text { SA9 Disruptive behaviour } \\
\text { disorders } \\
\text { SA93 Substance use } \\
\text { disorders } \\
\text { SA94 Internet addiction } \\
\text { disorder } \\
\text { SA10 Patterns } \\
\text { adolescence in } \\
\text { Of disorders with onset in } \\
\text { childhood/adolescence } \\
\text { SA101 Autism spectrum } \\
\text { disorder } \\
\text { SA102 } \\
\text { deficit/hyperactivity disorder } \\
\text { SA103 Specific Learning } \\
\text { Disorders } \\
\text { SAApp } \\
\text { Psychological experiences } \\
\text { that may require } \\
\text { clinical attention } \\
\text { SAApp1 Demographic } \\
\text { minorities } \\
\text { (ethnic, cultural, linguistic, } \\
\text { religious, political) } \\
\text { SAApp2 Lesbian, gay and } \\
\text { bisexual people } \\
\text { SAApp3 } \\
\text { incongruence }\end{array}$ \\
\hline
\end{tabular}


\begin{tabular}{|l|l|l|}
\hline & \\
\hline
\end{tabular}

The order of assessment of the three axes depends on the age of the subject. While with adult patients, the clinician has to assess first the P-axis, then the M-axis and finally the S-axis, with adolescent, child, and elderly patients, the clinician has to assess first the M-axis, then the P-axis (since, for example, in childhood and adolescence personality is an "emerging" dimension, still in the process of formation) and last the Saxis. Finally, the diagnostic assessment of early childhood (IEC, 0-3 years) is organised in a stand-alone way according to five axes (see Table 1; for an in-depth description, see Hope, Malberg, Steele, 2018).

Compared to the previous edition, PDM-2 has a stronger foundation in empirical research. It also includes contributions from the field of neuroscience and infant research. Other theoretical-clinical orientations (e.g. cognitive-behavioural or systemicfamilial) promote a truly accurate diagnostic formulation that considers each treatment project and the individual as a whole. Of particular relevance is the addition of assessment tools directly derived from the manual [particularly the Psychodiagnostic Chart (PDC-2) and its versions for each age group].

The PDM-2 diagnoses are "'prototypical', i.e. they are not based on the idea that a list of symptoms with equal weighting is sufficient to describe a diagnostic category (the 'polythetic' approach of the DSM), but on the assumption that the 'patient's clinical presentation may have varying degrees of similarity or overlap with the description of a prototype or 'ideal 'type' of a disorder. Moreover, although some sections refer to the psychopathological labels used in current diagnostic taxonomies, PDM-2 also highlights patients' internal, subjective experience presenting with such conditions. This approach does not regard pathology as a form of maladjustment in its own right: as we shall see, the $\mathrm{P}$-axis provides for a healthy level of personality organisation, everyone has the capacities that go to define the M-axis profiles of mental functioning, and many, in some circumstances, may experience the psychological experiences described in the S-axis. As Paolo Legrenzi (2018) has written, in the "psychological diagnosis" of the PDM-2, the focus is more on dimensionality than on categorical differences of the normal (or standard)/healthy/sick triad.

The M-axis of the PDM-2 offers a detailed description of an individual's mental functioning profile by examining a set of capacities (or 'mental 'functions') that define an individual's psychological health status (see also Lingiardi, Colli, Muzi, 2018). Suppose the $\mathrm{P}$-axis requires clinicians to examine the level of organisation and specific 
patterns/disorders of the patient's personality. In that case, the M-axis encourages them to consider and assess 12 specific areas of mental functioning (see list in Table 2) to evaluate all the elements that contribute to determining the level of organisation of the patient's personality. Although the M-axis is divided into 12 specific and differentiated mental functions, it is essential to remember that these are not independent of each other. Mental functioning should be conceived as a set of connected and integrated processes - a totality, a unicum, which, in the Aristotelian sense, can be operationalised into several contiguous categories. Each mental function is accompanied by descriptions that illustrate the different levels of functioning, from the healthiest to the most impaired, together with specific descriptors that also allow assessments at a quantitative level. Finally, a list of the most relevant assessment tools for that specific area is provided for each function.

As clinicians and researchers, teachers and supervisors, we realise every day that many young colleagues in training feel lost in a diagnostic world entirely entrusted to the biomedical area, experiencing the lack of a nosographic system articulated in a more psychological sense, which takes into account the pathological elements as well as the adaptive ones, the general elements as well as the individual ones (Lingiardi, 2018). PDM-2 aims to promote and emphasise the dynamic, relational and intersubjective aspects of diagnosis and to provide clinicians with an adequate explanatory framework to help them in the difficult task of understanding the complex clinical material they are confronted with within the framework of their daily practice. Without attention to these aspects, the diagnostic process loses its meaning and becomes the mere application of a routine. This risk undermines clinicians' professional identity and weakens and distorts their ability to describe and grasp the most salient features of a patient's mental functioning, also jeopardising the therapeutic relationship, which, as we know, is the factor that most influences the outcome of a treatment.

\section{References}

Frances, A. (2013). Diagnosis in psychiatry. Rethinking the DSM-5. Tr. it. Milan, Raffaello Cortina.

Freud, S. (1915). Introduction to psychoanalysis. Tr. It. in Opere, vol. 8. Boringhieri, Turin 1974.

Hoffman, I.Z. (2009). Doublethink on the way to "scientific legitimacy": The desiccation 
of human experience. Journal of the American Psychoanalytic Association, 57, 1043-1069.

Hope, A. M., Malberg, N., Steele, M. (2018). Mental health and developmental disorders in infancy and early childhood: The PDM-2. Psychoanalytic Psychology, 35, 328-338.

Jaspers, K. (1913). General psychopathology. Tr. It. II Pensiero Scientifico, Rome 1964. Legrenzi, P. (2018). How to make diagnoses: the goal of PDM-2. Giornale Italiano di Psicologia, XLV, 4.

Lingiardi, V. (2018). Diagnosis and destiny. Einaudi, Turin.

Lingiardi, V., Colli, A., Muzi, L. (2018). A clinically useful assessment of 'patients' (and 'therapists') mental functioning: Implications of the M-axis for the therapeutic alliance. Psychoanalytic Psychology, 35(3), 306-314.

Lingiardi, V., McWilliams, N. (2015). The psychodynamic diagnostic handbook - 2nd edition (PDM-2). World Psychiatry, 14, 2, 237-239.

Lingiardi, V., McWilliams, N. (Editors) (2017). The psychodynamic diagnostic handbook - 2nd edition (PDM-2). Guilford Press, New York.

McWilliams, N. (2011). Psychoanalytic diagnosis (2nd edition). English translation. Astrolabe, Rome.

PDM Task Force (2006). Psychodynamic Diagnostic Manual. Tr. It. Raffaello Cortina, Milan.

Shedler, J., Westen, D., Lingiardi, V. (2014). Personality assessment with the SWAP200, new edition. Raffaello Cortina, Milan.

Woolf, W. (1922). 'Jacob's room. Tr. It. Mondadori, Milan. 